\title{
A BRINCADEIRA COMO PERFORMANCE EM UM ESPETÁCULO PARA CRIANÇAS
}

\section{The play as performance in a play for children}

\author{
Diego de Medeiros Pereira \\ Universidade Federal de Santa Maria - UFSM \\ Mateus Junior Fazzioni \\ Universidade Federal de Santa Maria - UFSM ${ }^{1}$
}

Resumo: Neste texto, busca-se examinar e entender o "brincar" como um ato performativo que acontece em uma zona liminar, que não se encontra nem dentro e nem fora da subjetividade infantil. A elaboração deste estudo se faz por meio de revisão bibliográfica e análise do espetáculo "Atenção para a Chamada!", criado pelo Grupo de Estudos sobre Teatro e Infâncias (GETIs/CNPq), em 2017. Esses materiais serão discutidos tendo como primeiro plano a investigação das relações entre a brincadeira performativa da criança e o teatro contemporâneo.

Palavras-chave: Performance. Brincadeira. Teatro e Infâncias.

Abstract: In this text, the examination and understanding of "playing" as a performative act that happens in an edging zone, found neither in nor out of the childish subjectivity, is aimed. The elaboration of this study is made by a bibliographical review and the analysis of the play "Atenção para a Chamada!" (Attention to the Roll Calling), created by the Study Group on Theater and Childhoods (GETIs/CNPq), in 2017. This materials will be discussed with a major concern in the investigation os relation between the child's performative playing and contemporary theater.

Keywords: Perfomance. Playing. Theater and childhood.

\footnotetext{
${ }^{1}$ Bolsista PIBIC/CNPq. 
O presente artigo propõe reflexões a respeito da brincadeira infantil e de como ela pode ser proposta como ato performativo em um espetáculo de teatro feito por adultos para um público de todas as idades, com especial atenção para as crianças. Essa investigação foi elaborada pelo Grupo de Estudo sobre Teatro e Infâncias (GETIs/CNPq), do Departamento de Artes Cênicas da Universidade Federal de Santa Maria (UFSM), com o apoio do Programa Institucional de Bolsas de Iniciação Científica (PIBIC). O interesse pelo tema surgiu durante o estudo do texto "A criança é performer" (2010), de Marina Marcondes Machado, o qual nos instigou a pesquisar o espaço ocupado pela brincadeira na vida da criança e como propô-la em um espetáculo de teatro, uma vez que o GETls se encontrava em um processo de criação interessado em experimentar modos de acessar a criança por meio do teatro.

Neste texto, partimos de uma pesquisa bibliográfica para encontrar - conceito de performance que melhor se adeque a nossa compreensão sobre essa prática artística. Na sequência, buscamos compreender $\mathrm{o}$ ato de brincar da criança e estabelecer possíveis vínculos entre esse e a noção de espaço potencial, proposta por Winnicott (1975). Compreendendo a performance como um fenômeno artístico e humano e, nesse sentido, buscamos discutir se o ato de brincar da criança pode ser entendido como performance.

Posteriormente, por meio da análise e reflexão sobre a prática teatral desenvolvida no grupo de pesquisa, buscamos discutir como se dá esse ato de instauração da brincadeira pelo adulto em um espetáculo teatral, sem que exista uma representação e uma mimetização estereotipada da criança e do brincar.

Entendemos que este texto, ao problematizar possíveis interlocuções entre as práticas teatrais contemporâneas e o público infantil, pode contribuir com a ampliação dos estudos a respeito das infâncias, assim como das produções culturais direcionadas à criança, muitas delas alheias à cena atual e carentes de 
qualidade técnica, estética e artística, como, em geral, são os materiais voltados a esse público.

\section{Das noções de performance à brincadeira}

A noção de performance foi proposta no início do século $\mathrm{XX}$, ligada às vanguardas europeias históricas, principalmente ao futurismo. Posteriormente à segunda metade desse século, o hibridismo das manifestações artísticas possibilitou a propagação da performance pelo mundo ocidental e começaram a surgir reflexões a respeito dela a partir das práticas desenvolvidas em diferentes territórios das artes e fora deles.

No Brasil, Renato Cohen ${ }^{2}$, em seu livro "Performance como Linguagem" (2002), apresentou estudos que colocaram a performance com uma linguagem artística que se encontra próxima à arte teatral, propondo noções de tempo e espaço atemporal e não-

\footnotetext{
2 Renato Cohen (1956-2003) foi performer, diretor, pesquisador e professor do Programa de Comunicação e Semiótica da Pontifícia Universidade Católica de São Paulo (PUC) e do Departamento de Teatro da Universidade de Campinas (UNICAMP).
}

espacial, que se localizam para além do corpo do artista. Para o autor:

Apesar de sua característica anárquica e de, na sua própria razão de ser, procurar escapar de rótulos e definições, a performance é antes de tudo uma expressão cênica: um quadro sendo exibido para uma platéia não caracteriza uma performance; alguém pintando esse quadro, ao vivo, já poderia caracterizá-la. (COHEN, 2002, p. 28)

Para Cohen "[...] a performance se encontra entre as artes plásticas e as artes cênicas, sendo ela uma linguagem híbrida que possui características da primeira em sua origem e da segunda como finalidade" (2002, p. 30). Analisando seus estudos, é possível perceber que, para esse autor, a performance se encontra em um local que podemos definir como uma zona liminar (uma zona entre dois pontos, como uma linha imaginária em uma porta que separa os lados interno e externo do ambiente), nesse caso, uma zona limítrofe entre, pelo menos, duas linguagens artísticas (teatro e artes visuais).

Para se caracterizar como performance, o "evento" precisa acontecer em algum tempo e 
espaço, porém, não é exclusivamente isso que define a performance para Cohen, para ele a performance se caracteriza mais pelo modo como o artista se relaciona com a obra; uma "[...] arte do corpo em que se sistematizam essa significação corporal e a inter-relação com o espaço e a platéia" (COHEN, 2002, p. 44). Nesse ponto, sendo o seu corpo a "obra de arte" ele não representa, mas também não é ele mesmo em seu estado cotidiano.

Seu corpo vai servir de instrumento para a criação de uma nova relação com o espaço-tempo e com o público. Cohen completa: [...] quando um performer está em cena, ele está compondo algo, ele está trabalhando sobre sua "máscara ritual" que é diferente de sua pessoa do dia-a-dia. (2002, p. 58).

Ao propor um panorama histórico sobre essa prática, Cohen retrata que "[...] a performance está ideologicamente ligada à não-arte, proposta por Kaprow ${ }^{3}$, na medida

3 Allan Kaprow (1927-2006). Pintor estadunidense, um dos precursores, no final dos anos 1950 e 1960, do Happening e, nos anos 1970, das Atividades - obras com caráter de evento, cujo fim está em sua realização e não na apresentação para uma que, como nesta, vai contra o profissionalismo e a intencionalidade na arte" (2002, p. 46). Essa ligação com uma não-arte relaciona a performance com a live art $^{4}$, uma arte que busca se aproximar da vida, possibilitando à performance fazer rupturas com atribuições estéticas e elitistas. Surgindo, assim, uma noção de performance como uma "ritualização" dos atos comuns da vida: dormir, comer, movimentar-se, beber um copo de água, por exemplo.

Nesse sentido, a performance em Cohen se aproxima da vida ao passo que, alguns atos possam ser ritualizados, ainda que o autor não trate as ações cotidianas como performance. Para Cohen, a performance está entre alguns "[...] limites que separam vida e arte"

plateia. Foi, também, professor emérito no curso de Artes Visuais da Universidade da Califórnia.

${ }^{4}$ A live art trata da arte ao vivo e também a arte viva. É uma forma de se ver a arte em que se procura uma aproximação direta com o "aqui e agora", em que se estimula o espontâneo, o natural, em detrimento do elaborado, do ensaiado. A live art propõe uma ruptura que visa a dessacralizar a arte. A ideia é resgatar a característica ritual da arte, tirando-a de "espaços mortos", como museus, galerias, teatros, e a colocando numa posição "viva", modificadora. (COHEN, 2002, p. 38). 
(2002, p. 38). Esses limites são por nós entendidos como espaços presentes em uma zona liminar.

Com um olhar mais abrangente para o conceito de performance, temse 0 pensamento de Richard Schechner $^{5}$ e dos Estudos da Performance, que vêm atuando nesse campo desde os anos de 1970. Para ele, diferentes ações podem se caracterizar como performance, basta analisar esses atos como tal. A performance pode ser estudada como uma arte, uma manifestação humana ou, até mesmo, como ritual "[...] Qualquer comportamento, evento, ação, ou coisa pode ser estudado como se fosse performance e analisado em termos de ação, comportamento, exibição." (SCHECHNER, 2003, p. 39). O autor complementa: "[...] Tratar qualquer objeto, obra ou produto como performance - uma pintura, um romance, um sapato, ou qualquer outra coisa significa investigar o que esta coisa faz, corno

5 Richard Schechner é pesquisador e professor do departamento de Performance Studies, da New York University, associação filiada aos estudos da arte da performance. interage com outros objetos e seres." (2003, p. 28).

Para Schechner, a performance é mais que uma ação teatral, ela pode ser entendida como uma "categoria" abrangente, trata-se de "ações" humanas em diversas esferas, "Performances artísticas, rituais ou cotidianas" (2003, p. 27). Ou seja, as performances se encontram além das manifestações artísticas do teatro, dança e artes visuais, elas podem ser rituais, práticas esportivas, de entretenimento, papéis sociais e/ou ações do dia-a-dia, como as brincadeiras. Para Schechner,

Fazer performance é um ato que pode também ser entendido em relação a: Ser, Fazer, Mostrar-se fazendo, Explicar ações demonstradas. Ser é a existência em si mesma. Fazer é a atividade de tudo que existe, dos quasares aos entes sencientes e formações super galáticas. Mostrar-se fazendo é performar: apontar, sublinhar e demonstrar a ação. Explicar ações demonstradas é o trabalho dos Estudos da Performance.. (SCHECHNER, 2003, p. 25-26)

$\mathrm{Na}$ visão do autor "Algo 'é' performance quando os contextos histórico e social, a convenção e o 
uso, a tradição, dizem que é. Rituais, jogos e peças, e os papéis da vida cotidiana são performances porque a convenção, o contexto, o uso e a tradição assim dizem" (SCHECHNER, 2011, p. 12). Schechner reconhece a dificuldade de determinar o que é a performance levando em conta seu olhar abrangente sobre ela. Para conseguir qualificar a performance, o autor aponta que "[...] toda ação é uma performance." (2011, p.12) e essa compreensão depende de cada cultura. Para o autor, as performances acontecem em oito situações distintas:

1. na vida diária, cozinhando, socializando-se, apenas vivendo;

2. nas artes;

3. nos esportes e outros entretenimentos populares;

4. nos negócios;

5. na tecnologia;

6. no sexo;

7. rituais - sagrados e seculares;

8. na brincadeira.

(SCHECHNER, 2003, p. 29-30)

Dentre os diferentes conceitos, também encontramos os propostos por autores como Victor Turner (1974) e Clifford Geertz (1989) que retratam a performance como algo a ser apresentado para um outro.
Entendemos que, para as discussões estabelecidas neste texto, caberia, inicialmente, observar os aspectos da performance como "brincadeira", citada por Schechner e, depois, refletir sobre os modos como ela pode emergir em um espetáculo teatral para/com crianças.

\section{Da brincadeira à performance}

A brincadeira pode não ser uma ação "séria" para o adulto, mas para a criança ela assume um elevado grau de seriedade. Isso porque, quando a criança brinca, ela não realiza ações "de qualquer jeito" ou como um modo de "passar o tempo". A brincadeira para a criança é sua ação, seu "trabalho". É por meio da brincadeira que a criança experimenta, descobre e aprende sobre suas habilidades, gostos, sexualidade, gênero, papéis sociais, entre outros aspectos que a constituirão como sujeito no mundo.

Em meio a essas descobertas, surgem questionamentos que darão origem à diferentes saberes. Dessa forma, compreendemos a brincadeira como um ato no qual a criança usa 
seu corpo como meio para a estruturação de experiências. Sendo assim, a criança não pode ser concebida como um ser passivo no seu processo de formação, mas como um ator social, um ser humano completo com especificidades e que age na interação com o outro, com o meio, com um grupo social, como aponta Sarmento (2007). Segundo Borba,

É importante enfatizar que o modo próprio de comunicar do brincar não se refere a um pensamento ilógico, mas a um discurso organizado com lógica e características próprias, o qual permite que as crianças transponham espaços e tempos e transitem entre os planos da imaginação e da fantasia explorando suas contradições e possibilidades. Assim, o plano informal das brincadeiras possibilita a construção e a ampliação de competências e conhecimentos nos planos da cognição e das interações sociais, o que certamente tem conseqüências na aquisição de conhecimentos nos planos da aprendizagem formal. (BORBA, 2006, p. 38).

A brincadeira é mobilizadora da imaginação da criança e de suas criações. Por meio do brincar a criança altera as noções de tempo e espaço estabelecidas, isso porque, segundo Merleau-Ponty (1990), a criança vive uma experiência de vida em um tempo atemporal e uma não espacialidade. Assim como Cohen (2002) apresenta concepções acerca da performance como ação que altera as noções de tempo e espaço, podemos entender a brincadeira infantil como performance, justamente porque, como exposto, as noções de tempo e espaço também são alteradas no ato de brincar.

O fato da brincadeira surgir de um pensamento articulado à comportamentos pré-estabelecidos socialmente (repetição de modelos, representação de ações e tipos sociais coletados no cotidiano, expressão de sensações e sentimento advindos do seu contexto), também parece aproximar a brincadeira da performance, uma vez que Schechner (2003) aponta que as performances são feitas de comportamentos restaurados, presos no ser. Diante dessa proximidade estabelecida, chamaremos essa ação da criança de "brincadeira performativa".

Quando Schechner aponta que a brincadeira é uma situação na qual a performance pode aparecer, 
ele induz à compreensão de que o ser que desempenha essa brincadeira é performer. O performer é um ser que faz e se mostra fazendo algo. "Mostrar-se fazendo é performar: apontar, sublinhar e demonstrar a ação" (SCHECHNER, 2003, p. 26). Quando a criança brinca, ela está exercendo a ação, sendo performer, podendo, ainda, criar uma audiência ao exibir a sua brincadeira para o pai, para a mãe, para a professora, colegas, entre outros. Entender a criança como performer é importante para dimensionar a brincadeira performativa. Uma noção próxima à que estamos expondo é o conceito de "criança performer", apresentado pela pesquisadora brasileira, Marina Marcondes Machado (2010).

A demonstração da ação e a brincadeira em si, podem gerar repetições e, em alguns aspectos, essa brincadeira é formalizada. A criança ritualiza a brincadeira, uma vez que repete seus modos de "fazer a comidinha", "dirigir um carro", "colocar bonecas para dormir", entre outras ações; mesmo essa brincadeira que possui uma certa ritualização, pode ser entendida como performance. Isso porque, nem a formalização é capaz de quebrar com a vitalidade do ato de brincar.

O ser performer nunca é igual, o homem é mutável e a criança, ainda mais. A sua brincadeira é influenciada pelo mundo que ela está descobrindo. Dessa forma, seu modo de brincar com um mesmo objeto, por exemplo, sempre será diferente, pois não há na criança uma noção formada de "representação", tudo é novo, mesmo que ela já tenha realizado/experimentado. Segundo Merleau-Ponty (1990) a criança não representa "[...] a criança não vive no mundo com dois pólos do adulto despertado, ela habita uma zona híbrida, que é a zona da ambigüidade, do onirismo" (MERLEAU-PONTY, 1990, p. 223). Ou seja, a criança não vive como os adultos, que estabelecem duas maneiras de ser "[...] o realismo estrito senso e a intelectualização da experiência" (MACHADO, 2010, p.284). A criança não racionaliza e intelectualiza seu ato de brincar como representação, ela habita uma zona onde a brincadeira não é 
representacional e o realismo não precisa ser seguido. Imaginação e criação conduzem a criança à uma performance, na qual as noções de tempo e espaço do adulto se alteram conforme os contextos e situações. Machado aponta:

Pois se a criança pequena não é de nenhum modo representacional, também outras vias de acesso à sua maneira de ser, tais como sua corporalidade, brincadeiras e dizeres, devem ser revistas. No brincar de faz de conta, por exemplo, o realismo aparece imposto pela indústria cultural do brinquedo previamente estruturado, ou seja, podemos afirmar que o realismo é viés do ponto de vista adulto. (MACHADO, 2010, p. 129)

A criança pode ser entendida como criança performer, segundo Machado, pois existe em sua brincadeira a instauração de um espaço criativo, que pode ser entendido como um "espaço potencial" semelhante ao proposto por Winnicott. Nas palavras desse autor:

Introduzi os termos 'objetos transicionais' e 'fenômenos transicionais' para designar a área intermediária de experiência, entre o polegar e o ursinho, entre o erotismo oral e a verdadeira relação de objeto, entre a atividade criativa primária e a projeção do que já foi introjetado, entre o desconhecimento primário de dívida e o reconhecimento desta ('Diga: "bigado"'). Por essa definição, o balbucio do bebê e o modo como a criança mais velha entoa um repertório de canções e melodias enquanto se prepara para dormir, incidem na área intermediária enquanto fenômenos transicionais, juntamente com 0 uso que é dado aos objetos [...] (WINNICOTT, 1975, p. 14)

Além do objeto físico utilizado como elemento demarcador do espaço do eu e do não-eu, Winnicott considera outras possibilidades para a criação de um espaço intermediário entre a criança e o mundo, cita, por exemplo, a expressão musical, as cantigas de ninar, compreendidas como fenômenos transicionais que exercem a mesma função do objeto transicional. São espaços liminares entre realidade e ficcionalidade, entre agir e imaginar; realizar uma ação no espaço a partir de sua imaginação.

Para Pereira,

Esse lugar é o espaço, ao mesmo tempo psíquico e real, no qual uma atividade - a brincadeira, o jogo sem regras - pode produzirse, caso as condições sejam favoráveis. O jogo sem regras não tem nenhum objetivo e não se define no registro pulsional da relação de objeto. O brincar é visto por Winnicott como uma atividade 
constitutiva de uma determinada espécie de espaço e tempo psíquicos, que posteriormente, no desenvolvimento psíquico da criança, será o lugar da experiência cultural. (PEREIRA, 2015, p. 30)

É nesse espaço potencial que a brincadeira performativa acontece. É por meio dela que surgem os movimentos, gestos, ações, expressividade e criatividade na criança. A esse conjunto de experiências corporais MerleauPonty (1992) chamou de “corporeidade", uma vez que entende que o homem não pode ser definido apenas como um corpo material, mas sim como "fenômeno corporal", com linguagem, gestos e expressão.

Por que esse espaço onde a criança brinca e usa o corpo é potencial? Segundo Le Breton, "Pela corporeidade, o homem faz do mundo a extensão de sua experiência; transforma em tramas familiares e coerentes, disponíveis à ação e permeáveis à compreensão" (LE BRETON, 2007, p. 08). É por meio do corpo e das possíveis descobertas por ele possibilitadas no ato de brincar que a criança gera conhecimentos,

aprendizados, desenvolve-se e se potencializa como ser performer no mundo. A criança se apropria do universo ao redor por meio do seu corpo e suas ações partem das experiências corporizadas, dessa forma, ela é performer, pois para Schechner, "[...] a primeira qualidade da performance é a ação corporal”. (2001, on-line).

A experiência da criança não é objetiva; ela está antes do objetivo, está ligada a um estado de vivência e sentimento de prazer. A criança é um ser no mundo, um ser que pensa, age e se expressa. Contudo, possui limitações, por conta de seu corpo estar em processo de formação e das restrições impostas nos espaços de convívio - a escola, por exemplo, que limita movimentos e expressões. Mesmo nesse estado, a criança é uma pessoa apta a se comunicar e se expressar; para isso, utiliza-se do corpo, da gestualidade, dos gritos, choros e risos. Esses modos de "falar" estão permeados por uma teatralidade, tempo e espaço. Em diálogo com Machado:

[...] a criança pequena, performer de "outro do outro", pesquisadora de seus contornos, limites, 
espaços e indecisões. A

"espacialidade" surge então como palavra-chave, ao designar um espaço povoado por corpos, que delimita o espaço corpo próprio, chave da expressividade, da relação criança outro e da relação criança-mundo.

2010, p. 127)

Nesse espaço potencial, a brincadeira performativa possibilita interações com a espacialidade e com o outro, gerando experiências comunicativas. Como aponta Winnicott, "É no brincar, e talvez apenas no brincar, que a criança ou adulto fruem de sua liberdade de criação" (1975, p. 79). Como, portanto, aproveitar esse espaço potencial para criar e se comunicar?

$\mathrm{Na}$ busca pelo redimensionamento dessa brincadeira como um espaço de convívio, criação e comunicação, que a propusemos dentro de um espetáculo de teatro para crianças. $\mathrm{Na}$ reflexão que segue, tratamos de compreender como as atrizes e atores no trabalho "Atenção para a Chamada!", colocam-se como performers, uma vez que, em diferentes momentos do evento cênico, artistas e público são convocados a brincarem a partir de alguns

motes

previamente

estabelecidos.

\section{A brincadeira performativa no espetáculo}

Como trazer para um espetáculo de teatro o ato de brincar de modo não representacional? Como não representar a criança e nem a brincadeira, mas, sim, vivenciar esse estado performático/brincante no corpo do(a) ator/atriz em cena? O estudo da brincadeira como performance surgiu no Grupo de Estudo sobre Teatro e Infâncias (GETIs/CNPq) por meio de leituras, debates e discussões de pesquisas dedicadas às infâncias. Além das ações semanais em âmbito teórico, o grupo conta com um Laboratório de Experimentação Cênica, também realizado semanalmente.

No laboratório estudantes dos cursos de Licenciatura em Teatro e Bacharelado em Artes Cênicas, desenvolvem experimentos artísticos, investigando as relações entre teatro e diferentes infâncias por meio de um olhar crítico sobre as rotinas impostas às crianças. Desses 
experimentos surgiu, em 2017, o espetáculo "Atenção para a Chamada!" que retrata modos de agir aos quais as crianças estão submetidas, principalmente na escola, e os espaços de brincadeira que elas criam no seu cotidiano.

O processo de criação partiu do procedimento conhecido como "work in process", trabalho em processo. O estudo e conceituação do work in process foi realizado por Renato Cohen, em 1999, no livro "Work in progress na cena contemporânea". Para Machado, a criação através desse procedimento possibilita uma "não-hierarquização da criação e seus procedimentos" (2004, p. 20), o que, para o Grupo, propiciou a investigação de diferentes materialidades a partir de estímulos como: histórias pessoais, vídeos de crianças, músicas "infantis", histórias clássicas, personagens estereotipados, brincadeiras populares, entre outros materiais.

Durante a criação desse espetáculo, atores e atrizes foram estimulados(as) a buscarem um estado de brincadeira, um resgate de um "núcleo de infância", como propõe Bachelard (1988). O jogo criado entre alusões às ações rotineiras das crianças e a quebra de tais ações nos espaços de brincadeira, foi 0 suporte da dramaturgia que surgiu, aos poucos, na criação do trabalho.

Nesse sentido, não havia a construção de personagens, mas de "personas" (ou os próprios atores) jogando com as situações criadas pelo encadeamento das proposições cênicas. Um jogo que se aproxima de configurações contemporâneas da cena teatral, como se pode observar nas palavras de Paroni e Brisola:
A idéia é que o subtexto, ligado às personagens, deve ser substituído pela idéia de contexto, ligada à ação, de modo a dar uma função ao ator dentro de um percurso; explora conflitos suscitados nos interlocutores por situações particulares de seu próprio cotidiano [...]. $O$ ator contemporâneo assume essa responsabilidade que o transforma em criador, autor não só do texto, mas da própria escritura, que é o texto feito de palavras e também os gestos, os sons, o ritmo, a trajetória real da estória e a trajetória das subjetividades que dela participam.
(PARONI;
BRISOLA, 2007, p. 25-26) 
A construção do estado de brincadeira em cena, sempre esteve ligado à ação; agir e não representar. As explorações e experimentações dos(as) atores/atrizes na busca por esse estado, necessitou de amparo na preparação física. $O$ trabalho corporal/vocal era realizado no início de cada encontro buscando gerar um corpo atento às suas sensações, ao outro e as possíveis intervenções da plateia que se encontraria imersa no ambiente da cena, sem uma divisão entre performers e audiência.

A elaboração das cenas, nas quais essa brincadeira apareceria, era delineada a partir do que atores e atrizes ofereciam: histórias de suas infâncias, brincadeiras que conheciam, músicas, vivências que passaram na escola, entre outros materiais autobiográficos.

O trabalho em processo, entretanto, não estava apenas ligado às elaborações físicas, mas também ao desenvolvimento de uma performatividade. Por esse motivo, o espetáculo "[...] vai se caracterizar muito mais por uma extrojeção (tirar coisas, figuras suas) que por uma introjeção (receber a personagem)" (COHEN, 2002, p. 105). Isso porque os(as) atores/atrizes se colocam no processo como performers, vivenciando o acontecimento cênico não pelo intermédio de personagens, mas como sujeitos/artistas mobilizados(as) pelo jogo.

Nesse sentido, propomos trazer a criança à cena, mas sem uma representação da brincadeira ou da própria criança. Buscamos uma conexão com o público infantil a partir daquilo que the parece mais caro - 0 ato de brincar. Tentamos, também, despertar no público adulto as memórias das infâncias e as situações que passaram na escola.

A brincadeira performativa da criança-performer não pode ser representada, pois se trata de um momento performático, localizado num tempo-espaço próprio. Esse ato de brincar que altera as concepções de tempo e espaço surge por meio das relações estabelecidas entre a criança, o ambiente, o objeto/brinquedo e as outras crianças. Dessa forma, pareceu-nos que a única maneira de explorar essa brincadeira em cena, era com o(a) ator/atriz/performer se colocando em estado de brincadeira e... brincando. Como aponta Cohen 
"[...] o performer lida muito com o 'aqui-agora' e ter um contato direto com o público faz com que o trabalho com energia ganhe grande significação" (2002, p. 105). Sentimos isso a cada compartilhamento do espetáculo, quando em contato direto com o público que brinca conosco estabelecemos uma conexão que extrapola a esfera do representacional e adentra no espaço da vivência artística compartilhada.

Colocar-se como performers em cena possibilita aos(às) atores/atrizes uma vivência real da brincadeira performativa da criança (ou do adulto que brinca) e não uma representação dessa. A busca por essa brincadeira performativa viva no corpo dos(as) atores/atrizes foi possível com a criação de um estado de brincadeira, com a compreensão de que estamos performando. Compreendermo-nos como seres que realizam uma performance, é um dos primeiros passos para acessarmos a brincadeira no nosso corpo no momento da realização cênica. Perceber-se performer é reconhecer que ator e performance assumem papéis diferentes na cena, como aponta Patrice Pavis (1999):

[...] o performer realiza sempre uma façanha (uma performance) vocal, gestual ou instrumental, por oposição à interpretação e à representação mimética do papel pelo ator; num sentido mais específico, o performer é aquele que fala e age em seu próprio nome (como artista e pessoa) e como tal se dirige ao público, ao passo que 0 ator representa sua personagem e finge não saber que é apenas um ator de teatro. $O$ performer realiza uma encenação de seu próprio eu, o ator faz papel de outro. (PAVIS, 1999, p. 284285)

Outro ponto relevante da pesquisa de criação do experimento cênico, foi a busca por uma configuração que extrapolasse as formas tradicionais de se conceber o teatro para crianças, em geral arraigado na fábula, nos personagens estereotipados, na linearidade da narrativa, em uma estética "facilmente" acessada pela criança, com excesso de cores, movimentos e cantigas. Buscamos pautar nossa concepção do espetáculo em diálogo com a cena contemporânea, com proposições estéticas que buscam romper com os 
paradigmas de um teatro dramático.

Em diálogo com Machado:

O que é essencialmente pósdramático é a relação da encenação com o tempo e com o espaço: esse modo de fazer teatro não necessita de um texto dramatúrgico pronto, fechado, com começo, meio e fim radicalizando, prescinde até mesmo do texto - o que nos leva a um tipo de trabalho que apresenta uma bagunça, por assim dizer, entre começo, meio e fim; e nessa bagunça presenciamos rupturas, repetições, nonsense; não há lógica formal, diversas lógicas convivem, e isso implica em um tipo de recepção, por parte de quem assiste: 0 espectador encontra-se mais livre para interpretar, a seu modo, tudo que vive durante um ato performático. (MACHADO, 2010, p. 118)

A construção do espetáculo não seguiu a linearidade das peças teatrais convencionais. As cenas emergem da relação entre partituras físicas e motes para o jogo, sem textos pré-determinados, apenas um roteiro de "momentos". O texto teatral - não necessariamente falado surgiu durante a criação de cenas abertas (sem excesso de formalização/marcações) como mobilizador das ações físicas referentes ao estado da infância instaurado. As composições cênicas "brincam" com vivências pessoais e histórias da infância dos(as) atores/atrizes. Nesse sentido, estabelecemos, também, relações com o que afirma Garrocho:

[...] o que deve ser resgatado quando se pensa em teatro é o ato performático, ou seja, o exercício de viver o corpo numa situação de liberdade para a criação. Nos jogos dramáticos infantis, por exemplo, a criança brinca, joga com o corpo, age por motivação intrínseca. A matéria do teatro é a imagem, a voz, o corpo, o espaço e o tempo. A criança precisa ter contato com tudo isso. [...] $O$ teatro é uma dramaturgia de sons e imagens, de tempo e espaço, de ações poéticas enfim (GARROCHO apud MACHADO, 2010, p. 121).

Como uma forma de acessar o estado de infância, os(as) atores/atrizes se colocam como performers, brincando com o roteiro para gerar o evento cênico. A cada ensaio ou compartilhamento do espetáculo, o que se busca é encontrar o(a) artista/performer, para acessar os estados do ser criança, da brincadeira e da performance. Tentamos não cair em uma representação da brincadeira ou de uma criança, o que nos afastaria do caráter performativo da proposta 
cênica e da relação direta e verdadeira com o público, buscamos explorar a criação livre na brincadeira, fazendo emergir um espaço potencial.

Rotinas e brincadeiras de infância foram se atravessando em um roteiro com coreografias marcadas, mas, ao mesmo tempo, com momentos de improviso, com os textos, figurinos e partituras. Performers procurando em si e na brincadeira a poética dos primeiros anos de vida, resgatar algo do seu "ser criança" em um tempo atemporal; esse é um dos desafios a cada vez que compartilhamos o espetáculo.

Outro questionamento que surgiu no decorrer do processo foi: como fazer esse espetáculo voltado para um público de todas as idades, priorizando o contato com as crianças, de modo que elas participassem da brincadeira?. Esse é outro desafio: fazer as crianças se sentirem confiantes a ponto de participarem da brincadeira. Tornar perceptível os momentos "chatos" de rotinas em contraponto aos momentos prazerosos e criativos da brincadeira performativa. Buscou-se tirar a criança de seu lugar de espectadora "passiva" (como aquele imposto pela professora em sala de aula), possibilitando a ela ser performer na brincadeira com os(as) atores/atrizes. Quando esse jogo se estabelece, encontramos o que aponta Eckschmidt:

As crianças nos respondem com toda a genialidade de seus gestos e de sua imaginação, porque é brincando livremente que elas expressam sua criação! Criação que se concretiza com base no que vive dentro de cada uma dessas crianças - sua cultura, suas histórias e crenças - e na sua individualidade, do que tem de mais profundo em si! (ECKSCHMIDT apud MEIRELLES, 2015, p. 74)

O espectador, no caso a criança, sai de seu papel de agente receptor do espetáculo e passa a ser propositora, participando da brincadeira que compõe a cena. "Atenção para a Chamada!" é compartilhado, prioritariamente, em espaços escolares, muitas vezes dentro das próprias salas de aula das crianças e, nesses espaços, percebemos o quanto o corpo infantil é "institucionalizado". O espetáculo 
provoca as crianças a agirem e reagirem, em contraposição, as professoras tentam impedir as manifestações, pedem silêncio, lançam olhares, seguram algumas para não "entrarem" na cena, ainda que não haja uma divisão entre palco e plateia.

Na escola, a criança sofre, de certa forma, um processo de “castração de sua infância”. São impostas a ela maneiras de ser, de se comportar, de brincar... e, dessa forma, reduz-se sua habilidade de criança-performer criadora; a brincadeira deixa de ser a performance infantil, para se tornar, muitas vezes, mais uma ação rotineira e imposta. Esperamos que o espetáculo possa, de alguma maneira, restituir o espaço potente do brincar e crie um outro espaço a ser ocupado pelo teatro na vida das crianças e dos adultos com os quais compartilhamos o trabalho.

\section{Algumas reflexões finais...}

Ao mapear e estabelecer o conceito de performance encontramos relações dessa com 0 ato de brincar da criança e percebemos as aproximações na feitura do espetáculo, entendo essa ação como "brincadeira performativa". Passamos a ver a criança brincando como performer, uma “criança performer', que executa ações, vivendo e explorando diversos territórios de forma onírica e não representacional, com as noções de tempo e espaço se alterando em detrimento das situações.

Descobrimos o território híbrido e criativo no qual a brincadeira acontece de maneira potencializada; uma zona liminar entre a vida e a arte, espaço potencial no qual a criança coloca seu corpo como experiência e como modo de apropriação de conhecimentos e descobertas. Nesse jogo de interações do corpo da criança com o espaço, o tempo e com os demais corpos e objetos nascem experiências comunicativas, de fruição e criação.

$\mathrm{Na}$ compreensão desses conceitos, o espetáculo "Atenção para a Chamada!" propõe aos performers chegarem à brincadeira performativa, colocando-se em cena em um estado brincante ao invés de criarem

figuras infantis 
estereotipadas. A criança surge em cena por meio da memórias dos(as) atores/atrizes, do experimentar as possibilidades da brincadeira através da busca pela instauração do espaço potencial.

A proximidade com a criança é possível graças a liberdade na estrutura do espetáculo, que além de oferecer uma criação no aqui-agora com momentos de improviso, possibilita uma troca com o público e faz com que a brincadeira nunca deixe de ser viva tanto no espaço como nos corpos dos atores. Dar liberdade ao público (na maioria das vezes criança) de participar do espetáculo é entender que a brincadeira performativa só pode acontecer assim, por meio da verdadeira interação entre os corpos com o espaço e com o que nele se apresenta.

Parece-nos que uma preocupação dos trabalhos voltados a esse público deveria ser o de ampliar os modos como o teatro é percebido pelos pais $\mathrm{e}$ professores(as) - pessoas que em geral levam as crianças ao teatro. $O$ senso comum de que o teatro para crianças precisa "ensinar algo" ou trazer uma "moral da história" não deveria ser reafirmado pelos grupos que se dedicam a esse gênero. É preciso, do nosso ponto de vista, alargar as referências, propor novos formatos, provocar os sentidos para além da fábula, assimilando aspectos da cena contemporânea e estabelecendo novas relações com o público infantil.

Recebido em 14/09/2018

Aceito em 20/10/2018

\section{Referências Bibliográficas}

BACHELARD, Gaston. A poética do devaneio. São Paulo: Martins Fontes, 1988.

BORBA, Ângela Meyer. O brincar como um modo de ser e estar no mundo. In: BRASIL, MEC/SEB Ensino fundamental de nove anos: orientações para a inclusão da criança de seis anos de idade. Brasília: Ministério da Educação, Secretaria de Educação Básica, 2006.

COHEN, Renato. Performance como linguagem. São Paulo: Perspectiva, 2002.

COHEN, Renato. Work in progress na cena contemporânea: criação, encenação e recepção. São Paulo: Perspectiva, 1999. 
GEERTZ, Clifford. A interpretação das culturas. Rio de Janeiro: Guanabara Koogan, 1989.

LE BRETON, David. Adeus ao corpo. Campinas: Papirus, 2007.

MACHADO, Marina Marcondes. A criança é performer. Educação e Realidade. Porto Alegre: UFRGS, v. 35. n. 02. p. 115-138, 2010.

MACHADO, Marina Marcondes. Cacos de infância: teatro da solidão compartilhada. São Paulo: Annablume/FAPESP, 2004.

MEIRELLES, Renata. Território do brincar: diálogo com escolas. São Paulo: Instituto Alana, 2015.

MERLEAU-PONTY, Maurice. O visível e o invisível. São Paulo: Perspectiva, 1992.

MERLEAU-PONTY, Maurice. Merleau-Ponty na Sorbonne/Resumo de cursos: Filosofia e Linguagem. Campinas: Papirus, 1990.

PARONI, Maurício; BRISOLA, Ziza. Aqui ninguém é inocente: projeto Voltaire de Souza o intelectual periférico. São Paulo: Alameda, 2007.

PAVIS, Patrice. Dicionário de teatro. São Paulo: Perspectiva, 1999.

PEREIRA, Diego de Medeiros. Teatro na formação de professores da Educação Infantil. Curitiba: Appris, 2015.
SARMENTO, Manuel Jacinto; VASCONCELOS, Vera Maria Ramos de. (Org.) Infância (in)visível. Araraquara: Junqueira \& Marin Editores, 2007.

SCHECHNER, Richard. Performers e espectadores: transportados e transformados. Moringa Artes do Espetáculo. João Pessoa: UFPB. vol 2. n1. p. 155-186, 2011.

SCHECHNER, Richard. O que é Performance?. O Percevejo v. $11 \mathrm{n}$. 12. Rio de Janeiro: Unirio. pp. 25-50, 2003.

SCHECHNER, Richard. O que é a performance - entrevista com Richard Schechner, 2001.

Disponível em: http://scalar.usc.edu/nehvectors/wips/ rs-portuguese

TURNER, Victor. O processo ritual: estrutura e anti-estrutura. São Paulo: Vozes, 1974.

WINNICOTT, Donald. O brincar \& a realidade. Rio de Janeiro: Imago, 1975. 
Moringa Artes do Espetáculo, João Pessoa, UFPB, v. 10 n. 1, jan-jun/2019, p. 129 a 148

\section{moringa}

